\title{
Susceptibility of Selected Grape Cultivars and Tree Fruit to Silverleaf Whitefly (Bemisia argentifolii) Colonization
}

\author{
Charles G. Summers ${ }^{1}$, Albert S. Newton, Jr. ${ }^{2}$, and Kyle R. Hansen ${ }^{3}$ \\ Department of Entomology, University of California, Davis, CA 95616
}

Additional index words. stone fruit, pome fruit, silverleaf whitefly hosts, Vitis vinifera, kiwifruit, nut crops

\begin{abstract}
Six table grape (Vitis vinifera L.) cultivars and 10 species of tree fruit were evaluated in cage tests to determine their susceptibility to colonization by the silverleaf whitefly (Bemisia argentifolii Bellows and Perring). The table grape cultivars Thompson Seedless, Perlette, Flame Seedless, Ruby Seedless, Christmas Rose, and Redglobe were all colonized. In a field nursery, with naturally occurring silverleaf whitefly populations, 'Zinfandel', 'Sirah', and 'Chardonnay' were more heavily colonized than were 'Merlot', 'Thompson Seedless', or 'Redglobe'. The tree crops 'Kerman' pistachio (Pistacia vera L.), 'Calimyrna' fig (Ficus carica L.), 'Nonpareil' almond [Prunus dulcis (Mill.) D.A. Webb], and 'Fuyu' persimmon (Diospyros kaki L.) were colonized in cage tests. Silverleaf whitefly failed to establish colonies on caged 'O'Henry' peach [Prunus persica (L.) Batsch.], 'Fantasia' nectarine [P. persica (L.) Batsch. var. nectarina (Ait.f.) Maxim.], 'Casselman' plum (P. salicina Lindl.), 'Tilton' apricot ( $P$. armeniaca L.), 'Granny Smith' apple (Malus domestica Borkh.), and 'Hayward' kiwifruit [Actinidia delicoisa (A. Chevalier) C.F. Liang et A.R. Ferguson].
\end{abstract}

For several years, two populations of sweetpotato whitefly [Bemisia tabaci (Gennadius)] in the United States have been distinguished as "strain A (cotton strain)" and "strain B (poinsettia strain)." Perring et al. (1993a) provided evidence that the two strains, although morphologically similar, are distinct species and proposed that the whitefly previously known as B. tabaci "strain B" be designated silverleaf whitefly. Bellows et al. (1994) presented additional evidence for considering strain B a separate species and proposed the scientific name Bemisia argentifolii.

Silverleaf whitefly is more destructive than sweetpototo whitefly (Byrne and Miller, 1990; Perring et al., 1992, 1993a). In 1991, silverleaf whitefly caused more than $\$ 500$ million in losses to agricultural production across Arizona, southern California, Florida, Georgia,

Received for publication 26 Nov. 1994. Accepted for publication 27 Apr. 1995. We gratefully acknowledge the assistance of Debbie Estrada, Tricia Swanson, Bill Barnett, Nick Dokoozlian, and Richard Rice in conducting this study. Portions of the study were supported by the California Table Grape Commission and the California Tree Fruit Agreement. Nick Dokoozlian, Louise Ferguson, Scott Johnson, Richard Rice, and Frank Zalom improved the manuscript with their helpful comments and suggestions. The cost of publishing this paper was defrayed in part by the payment of page charges. Under postal regulations, this paper therefore must be hereby marked advertisement solely to indicate this fact.

${ }^{1}$ Associate Entomologist; to whom reprint requests should be addressed. Current address: Univ. of California, 9240 S. Riverbend Ave., Parlier, CA 93648.

${ }^{2}$ Staff Research Associate.

${ }^{3}$ Agricultural Futures Summer Intern.
Louisiana, New Mexico, and Texas (Perring et al., 1993b).

Silverleaf whitefly was found in the San Joaquin Valley in Fall 1992 (Gruenhagen et al., 1993). At immediate risk of infestation and injury are various field and vegetable crops, including alfalfa (Medicago sativa $\mathrm{L}$.), muskmelon (Cucumis melo L.), cotton (Gossypium hirsutum L.), tomato (Lycopersiconesculentum Mill.), squash (Cucurbita spp.), and cole crops (Brassica oleracea L.). All are known hosts in other areas of the United States. Little is known, however, regarding the susceptibility of California's 265,000 ha of grapes and 280,000 ha of tree fruit. Considerable confusion exists in the literature regarding the host status of many of these plants, which is exacerbated by the confusion in taxonomy surrounding the genus Bemisia (Bellows et al., 1994). Silverleaf whitefly appears to have a much broader host range than does sweetpotato whitefly (Byrne and Miller, 1990; Gill, 1992; Perring et al., 1992). Grapes are not listed as a host of sweetpotato whitefly (Greathead, 1986; Mound and Halsey, 1978), but moderate to heavy infestations of silverleaf whitefly were reported on 'Perlette' and 'Flame Seedless' in the Coachella Valley of California in 1992 (N. Dokoozlian, personal communication). The host status of another popular table grape, 'Thompson Seedless', is unknown. Peach, nectarine, and pistachio are all described as nonhosts of silverleaf whitefly, while apple and pear (Pyrus communis L.) are reported to be preferred hosts (Univ. of California, 1993).

This paper reports the results of controlled studies conducted to determine the susceptibility of selected grape cultivars and tree fruit to silverleaf whitefly colonization. We also report the results of field observations of natu- ral colonization of grapes and tree fruit by silverleaf whitefly.

\section{Materials and Methods}

Cage studies. Studies were conducted on established trees and vines at the Univ. of California Kearney Agricultural Center, Parlier, Fresno County, Calif., during July and Aug. 1993. The table grape cultivars chosen represent the majority of the acreage grown in the San Joaquin Valley. The tree crops were selected as representative of those grown in the region. Newly emerged adult whiteflies, 20 males and 20 females from a greenhouse colony reared on cotton, were placed in vials that were closed with a snap-top lid. Vials containing the whiteflies were transported to the field in an ice chest. A flexible sleeve cage $(39 \mathrm{~cm}$ long $\times 18 \mathrm{~cm}$ in diameter), constructed of fine-mesh nylon-organdy with a drawstring at each end, was placed over the terminal of a branch or cane of the test plant and a $4-\mathrm{cm}$ wide strip of foam rubber secured around the branch at each end of the cage. Caged branches or canes contained leaves ranging from fully mature to newly expanding. A vial containing the whiteflies was placed into each cage. The drawstrings were secured around the foam and tied, making a tight seal, thereby preventing whitefly escape. The whiteflies were then released from the vial by compressing the cage from the exterior and removing the vial lid. Three cages were placed on each of four trees or vines and each tree or vine was considered a replication.

Sampling began 7 days after infestation and continued at weekly intervals for 21 days. At each sampling interval, one cage from each replicate was removed by cutting the branch or cane at the proximal end of the cage and returning it to the laboratory. The caged terminals were chilled at $5 \mathrm{C}$ for $1 \mathrm{~h}$ to slow the activity of any adults present. The cages were removed and searched together with the foliage for the presence of live adults. The abaxial surface of each leaf was then searched microscopically and the number of silverleaf whitefly eggs and nymphs was recorded. To compensate for difference in leaf size among the grape cultivars and tree crops evaluated, leaf area was determined with a LI-COR LI-3000 leaf area meter (Lambda Instruments Corp., Lincoln, Neb.). Eggs and nymph counts are reported as number per $100 \mathrm{~cm}^{2}$ of leaf surface. To determine if naturally occurring infestations were present, four uncaged canes or branch terminals of similar foliage age and phenology to those enclosed in cages were removed on each sample date from the same vine or tree containing the cages and the abaxial leaf surface searched microscopically for eggs and nymphs.

Field observations. In Sept. 1994, a commercial nursery in Kern County, containing rooted cuttings of table and wine grape cultivars, was heavily infested with silverleaf whitefly. Individual cultivars were sampled by selecting five leaves at random from each of five vines. The leaves were placed in plastic bags, returned to the laboratory and the abaxial 
surface searched microscopically for nymphs. The leaf area was then determined as already described, and counts are reported as the number of nymphs per $100 \mathrm{~cm}^{2}$ of leaf surface. Whenever possible, grapes and tree fruit adjacent to silverleaf whitefly-infested fields were checked for natural infestations and colonization.

Statistical analysis. The effect of species or cultivar on the number of eggs and nymphs was determined by analysis of variance based on the 21-day counts. Means were separated by Fisher's protected least significant difference (LSD) (Abacus Concepts, 1989).

\section{Results and Discussion}

Grapes. The six table grape cultivars tested were all susceptible to silverleaf whitefly colonization. There was no significant difference $(P>0.10)$ in the number of eggs (Table 1$)$ among the grape cultivars; however, a slight but significant $(P<0.10)$ trend in the number of nymphs existed (Fig. 1). 'Thompson Seedless' and 'Flame Seedless' supported a significantly larger population of nymphs than did 'Christmas Rose' or 'Redglobe'. Nymphal populations on 'Perlette' and 'Ruby Seedless' were intermediate. This pattern may reflect a within life stages. $\mathrm{LSD}=0.761$ for eggs, 0.360 for nymphs difference in the parentage of the cultivars. 'Ruby Seedless', 'Christmas Rose', and 'Redglobe' were derived from several seedling crosses with 'Emperor', while 'Perlette' and 'Flame Seedless' were derived from crosses of several cultivars with 'Thompson Seedless' (Brooks and Olmo, 1972; Olmo and Koyama, 1981, 1983). No eggs or nymphs were found on leaves from any of the uncaged controls.

In samples taken from the Kern County grape field nursery, silverleaf whitefly showed a strong cultivar preference, with 'Zinfandel' the most heavily infested (Table 2). The wine grape cultivars, with the exception of 'Merlot', were more heavily colonized than the table grape cultivars Thompson Seedless and Redglobe or the rootstocks $140 \mathrm{Ru}$ and $5 \mathrm{BB}$ (Table 2). The 'Merlot' vines were within a few meters of the 'Zinfandel' vines but had only a fraction of the nymphal population. The rootstock Teleki $5 \mathrm{C}$, $\approx 50 \mathrm{~m}$ from the 'Zinfandel', also was heavily infested. Based on the number of nymphs present and the overlap in age-class structure of the population, there appeared to have been several generations since the initial infestation. All material was planted into the nursery in Spring 1994 as bare wood. The infestation arose from

Table 1. Analysis of variance for differences in silverleaf whitefly colonization on selected grape cultivars and tree crops.

\begin{tabular}{|c|c|c|c|c|c|}
\hline \multirow{3}{*}{$\begin{array}{l}\text { Sources of } \\
\text { variation }\end{array}$} & \multirow{2}{*}{\multicolumn{2}{|c|}{ df }} & \multicolumn{3}{|c|}{ Mean squares } \\
\hline & & & \multicolumn{2}{|c|}{ Grapes } & \multirow{2}{*}{$\frac{\text { Trees }^{z}}{\text { Nymphs }^{y}}$} \\
\hline & Grapes & Trees & Eggs & Nymphs & \\
\hline Replications & 3 & 3 & $0.532^{\mathrm{Ns}}$ & $0.077^{\mathrm{Ns}}$ & $0.494^{\text {Ns }}$ \\
\hline Cultivar/crop & 5 & 3 & $0.363^{\mathrm{NS}}$ & $0.330^{*}$ & $0.584^{\mathrm{Ns}}$ \\
\hline Error & 15 & 9 & 0.255 & 0.099 & 0.563 \\
\hline
\end{tabular}

${ }^{\mathrm{z}}$ Only fruit trees on which nymphs were found were included in the analysis.

${ }^{\mathrm{y} E g g}$ counts on tree crops were too low to analyze.

ss, "Nonsignificant or significant at $P<0.10$, respectively.

an unknown external source and the cultivars were all equally exposed. The 'Zinfandel' vines were located near the center of the nursery, ruling out an edge effect as the reason for this cultivar being more heavily infested than the others. Factors, such as vine vigor, heritage, and rootstock, may all affect individual cultivar response to silverleaf whitefly susceptibility and colonization. Additional research is needed to determine the effects of these components.

During 1994, we noticed light to moderate infestations of silverleaf whitefly in commercial vineyards, adjacent to heavily infested cotton in Kern and Tulare counties, on 'Redglobe', 'Thompson Seedless', 'Fantasy', and 'Christmas Rose'. In 1993, 'Harmony' grape was moderately infested in a Fresno County nursery (Summers et al., 1995).

Tree fruit. 'O'Henry' peach, 'Fantasia' nectarine, and 'Casselman' plum were free of eggs and nymphs. The study was repeated a second time, to confirm their lack of susceptibility to colonization, and again we found no eggs or nymphs. However, we did find fourthinstar silverleaf whitefly nymphs on leaves of 'Marianna 2624' (P. cerasifoli J.R. Ehrh. X P. munsoniana F.W. Wright \& Hedr.) rootstock suckers in a commercial orchard, but nymphs

HortScience, Vol. 30(5), August 1995

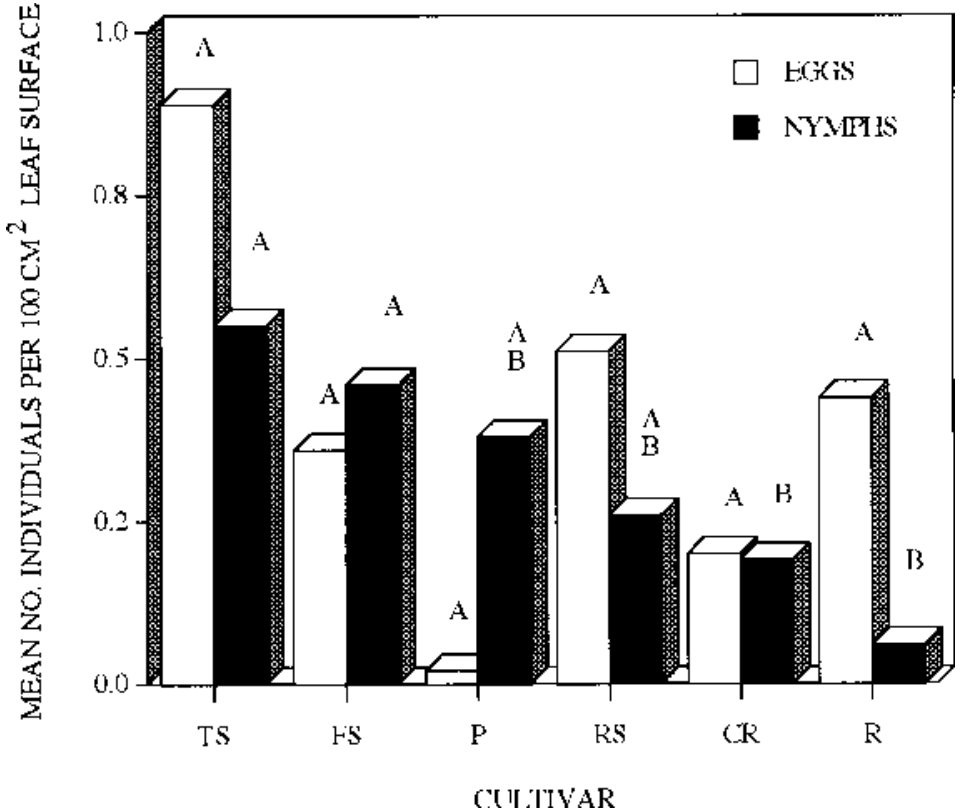

Fig. 1. The mean number of silverleaf whitefly eggs and nymphs per $100 \mathrm{~cm}^{2}$ of leaf surface in six grape cultivars. TS = 'Thompson Seedless', FS = 'Flame Seedless', P = 'Perlette', RS = 'Ruby Seedless', CR $=$ 'Christmas Rose', $\mathrm{R}=$ 'Redglobe'. Mean separations by LSD at $\alpha \leq 0.10$. Comparisons are valid only

were absent on leaves of the 'Santa Rosa' scion. Neither eggs nor nymphs of silverleaf whitefly were found on 'Granny Smith' apple or 'Hayward' kiwifruit. Apple had previously been reported as a preferred host (Univ. of California, 1993). The abaxial leaf surface of kiwifruit is highly pubescent and this may interfere with whitefly oviposition or settling of the crawlers. We found one egg, but no nymphs, on 'Tilton' apricot. In the absence of any nymphal development, it is unlikely that apricot is an acceptable host, but its status as a host is still in question. 'Nonpareil' almond, 'Kerman' pistachio, 'Calimyrna' fig, and 'Fuyu' persimmon supported silverleaf whitefly populations of $0.91,0.18,0.09$, and 0.17 nymphs per $100 \mathrm{~cm}^{2}$, respectively. There was no significant difference $(P>0.05)$ in the number of nymphs per $100 \mathrm{~cm}^{2}$ of leaf surface among these tree crops (Table 1). Summers et al. (1995) earlier found flowering almond $(P$. triloba Lindl.) colonized by silverleaf whitefly nymphs. Eggs were found on pistachio, but not on fig, almond, or persimmon. Egg counts

Table 2. Mean ( $\pm \mathrm{sE})$ number of silverleaf whitefly nymphs per $100 \mathrm{~cm}^{2}$ of leaf surface on selected grape cultivars from a Kern County, Calif., field nursery $(1994, \mathrm{n}=25)$.

\begin{tabular}{lc}
\hline Cultivar & No./100 $\mathrm{cm}^{2}$ of leaf \\
\hline Zinfandel $^{\mathrm{z}}$ & $336 \pm 67.1$ \\
Sirah $^{\mathrm{z}}$ & $129 \pm 47.5$ \\
${\text { Teleki } 5 \mathrm{C}^{\mathrm{y}}}_{\text {Chardonnay }^{\mathrm{z}}}$ & $89 \pm 34.6$ \\
$5 \mathrm{BB}^{\mathrm{y}}$ & $25 \pm 6.5$ \\
$140 \mathrm{Ru}^{\mathrm{y}}$ & $6.3 \pm 2.2$ \\
Merlot $^{\mathrm{z}}$ & $4.5 \pm 1.6$ \\
Thompson Seedless $^{\mathrm{x}}$ & $3.3 \pm 1.4$ \\
Red Globe $^{\mathrm{x}}$ & $2.1 \pm 1.3$ \\
\end{tabular}

${ }^{2}$ Wine grape.

'Rootstock.

xTable grape. 
on the tree crops were too low to analyze. Fig was previously reported as a host of sweetpotato whitefly (Greathead, 1986) and silverleaf whitefly (Summers et al., 1995). Summers et al. (1995) found Chinese pistache (P. chinensis Bunge.) lightly infested (one to two per leaf) with silverleaf whitefly nymphs. Pistachio, which had been previously reported as a nonhost (Univ. of California, 1993), and persimmon are new hosts of silverleaf whitefly. No eggs or nymphs were found on any of the uncaged controls.

During 1994, silverleaf whitefly colonized leaves of orange [Citrus sinensis (L.) Osbeck.] and avocado (Persea americana C.F. Gaertn.) in commercial orchards, adjacent to heavily infested cotton fields, in Kern and Tulare counties.

Pest management implications. Polyphagous insect species have a range of fitness on various hosts (Byrne and Bellows, 1991). Moving an insect from an established host to a new one, without permitting it time to adapt, generally places it at a temporary survival and reproductive disadvantage. Following the initial infestation of the new host, nymphal development may be slow and survival rates low. After several generations on a new host, however, large populations may develop. Grapes and some tree fruit, by virtue of their susceptibility to colonization, are potentially at risk of injury. This potential was demonstrated in the Kern County grape nursery where silverleaf whitefly populations, after several generations on grapes, reached damaging levels on 'Zinfandel'. Leaves were curled, distorted, and covered with honeydew and sooty mold; the latter may interfere with photosynthesis (Byrne et al., 1990). Silverleaf whitefly feed- ing defoliated 'Zinfandel'. Dokoozlian (personal communication) found reduced carbohydrate reserves in the roots of heavily infested 'Perlette' and 'Flame Seedless' grapes in the Coachella Valley of California.

The severity of silverleaf whitefly injury will depend on such factors as time of infestation and number of colonizing adults. Vineyards or orchards infested early in the season would likely sustain more damage than those infested late because of the increased number of possible generations. Vineyards or susceptible tree crops (fig, almond, pistachio, or persimmon) planted adjacent to highly preferred crops such as muskmelons or cotton are at a greater risk of infestation, particularly following harvest or plow down of these hosts, than those planted adjacent to a nonhost crop.

\section{Literature Cited}

Abacus Concepts. 1989. SuperANOVA 1.01. Abacus Concepts, Berkeley, Calif.

Bellows, T.S., Jr., T.M. Perring, R.J. Gill, and D.H Headrick. 1994. Description of a species of Bemisia (Homoptera: Aleyrodidae). Ann. Entomol. Soc. Amer. 87:195-206.

Brooks, R.M. and H.P. Olmo. 1972. Register of new fruit and nut cultivars. 2nd ed. Univ. of California Press, Berkeley.

Byrne, D.N. and T.S. Bellows, Jr. 1991. Whitefly biology. Annu. Rev. Entomol. 36:431-457.

Byrne, D.N., T.S. Bellows, Jr., and M.P. Parrella. 1990. Whiteflies in agricultural systems, p. 227261. In: D. Gerling (ed.). Whiteflies: Their bionomics, pest status and management. Intercept, Wimborne, U.K.

Byrne, D.N. and W.B. Miller. 1990. Carbohydrate and amino acid composition of phloem sap and honeydew production by Bemisia tabaci. J. Insect Physiol. 36:433-439.
Gill, R.J. 1992. A review of the sweetpotato whitefly in southern California. Pan-Pacific Entomol. 68:144-152.

Greathead, A.H. 1986. Host plants, p. 17-25. In: M.J.W. Cock (ed.). Bemisia tabaci-A literature survey on the cotton whitefly with an annotated bibliography. CAB Intl. Inst. of Biological Control, Silwook Park, Ascot Berks., U.K.

Gruenhagen, N.M., T.M. Perring, L.G. Bezark, D.M. Daoud, and T.F. Leigh. 1993. Silverleaf whitefly present in the San Joaquin Valley. Calif. Agr. 47(1):4-6.

Mound, L.A. and S.H. Halsey. 1978. Whitefly of the world. British Museum of Natural History, London.

Olmo, H.P. and A.T. Koyama. 1981. 'Redglobe' grapevine. U.S. Patent Plant 4787. 10 Nov. Int. Cl. ${ }^{3} \mathrm{~A} 01 \mathrm{H} 5 / 00$.

Olmo, H.P. and A.T. Koyama. 1983. 'Christmas Rose' grapevine. U.S. Patent Plant 5056. 31 May Int. Cl. ${ }^{3} \mathrm{~A} 01 \mathrm{H}$ 5/00.

Perring, T.M., A.D. Cooper, and D.J. Kazmer. 1992. Identification of the poinsettia strain of Bemisia tabaci (Homoptera: Aleyrodidae) on broccoli by electrophoresis. J. Econ. Entomol. 85:12781284.

Perring, T.M., A.D. Cooper, R.J. Rodriguez, C.A. Farrar, and T.S. Bellows, Jr. 1993a. Identification of a whitefly species by genomic and behavioral studies. Science 259:74-77.

Perring, T.M., C.A. Farrar, T.M. Bellows, Jr., A.D. Cooper, and R.J. Rodriguez. 1993b. Evidence for a new species of whitefly: UCR findings and implications. Calif. Agr. 47(1):7-8.

Summers, C.G., P. Elam, and A.S. Newton. 1995. Colonization of ornamental landscape plants by Bemisia argentifolii Bellows and Perring (Homoptera: Aleyrodidae). Pan-Pacific Entomol. (In press.)

University of California. 1993. A new whitefly in gardens and farms. Statewide IPM Project Leaflet. Univ. of California, Davis. 